\title{
Research on importing production information into Manufacturing Execution System of Precast Concrete factory based on Building Information Modeling
}

\author{
Zhenlei Guo ${ }^{1, *}$, Feihua YANG ${ }^{1}$, Jiayang Zhang ${ }^{1}$, and Weixuan Zhao ${ }^{1}$ \\ ${ }^{1}$ Academy of Green Building Technology, Beijing Building Materials Academy of Sciences Research, Beijing 100041, China
}

\begin{abstract}
Building Information Modeling in Precast Concrete factory should consider the split design and production as a whole, so we should pay attention to import the production information into MES and achieve enterprise level application. This paper studied two methods of importing production information to Manufacturing Execution System, namely DXF drawing and U file. This paper studied how to match information of DXF drawing with MES's layer, text information and title bar. This paper also studied the correct format of $U$ file and the information that can be resolved by MES. The feasibility of this two methods was verified through the prefabricated building project "Jin-an Hong Bao 7\#", and the types of prefabricated components, information quality, efficiency and cost of the two methods are compared. Dxf drawing is able to cover all kinds of precast components, easy for new comers to master, but the drawing efficiency is low. Currently, $U$ file only supports composite floor slab, and it has a long training period, but it also has extremely low error rate and extremely high drawing efficiency.PC factory should continue to improve $u$ file, which can greatly improve work efficiency and reduce engineering errors.
\end{abstract}

\section{Introduction}

Prefabricated building has advantages such as high construction efficiency, low energy consumption and low environmental impact ${ }^{[1]}$. In 2016, General Office of the State Council of the People's Republic of China clearly proposed to vigorously develop prefabricated building and make prefabricated building account for $30 \%$ of the floor area of new buildings within around 10 years ${ }^{[2]}$. With prefabricated building's gradual stepping on the right track, numerous architectural design, construction enterprises, etc. have entered precast concrete (PC) field, which sets off a craze for PC factory investment \& development nationwide, driving the rapid development of the PC market ${ }^{[3]}$.

Building information model (BIM) is digital expression of physical characteristics and functional characteristics of construction works. It not only eliminates information transmission barriers, but also provides a $3 \mathrm{D}$ visual management platform that can be used for data interaction ${ }^{[4]}$.

Theoretically, BIM technology is able to integrate various relevant information and data models from building design, production, construction, operation and maintenance. In addition, it is also able to realize effective transmission and sharing of data among different project stages and departments ${ }^{[5]}$. However, in fact, despite there are certain research and practice on the BIM technology of PC factory at present, they are basically staying in deepening and demonstration level with neither overall deepening \& production applications nor effective technical measures for importing production information into MES.

To promote coordinated development of intelligent construction and building industrialization, thirteen departments including Ministry of Housing and Urban-Rural Development and National Development and Reform Commission issued the following proposal jointly: Accelerate digital and intelligent upgrade of component production to realize less-manned and even unmanned factories. Accelerate the application of technologies such as intelligent human-computer interaction, intelligent logistics management, additive manufacturing as well as intelligent equipment ${ }^{[6]}$.

To promote digital and intelligent upgrade of the production of PC factory, it is necessary to realize digitization and intellectualization from the source, i.e. detailed design drawing needs to be imported into the production equipment. This paper studies two effective methods for importing production information into MES, namely, drawing Dxf drawing and preparing $\mathrm{U}$ file.

\section{Drawing Dxf Drawing}

Dxf (Drawing Exchange Format) is a file format developed by Autodesk for CAD data exchange between Auto CAD and other software ${ }^{[7]}$, and it needs to be drawn manually.

Since MES imports precast component information by analyzing the layer information of the graphics and text in 
Dxf drawings, it is necessary to assign clear layer properties to all graphics and text in drawings, and such properties shall not be crossed.

\subsection{Graphic Information}

Precast component needs to be subject to detailed design based on the construction requirements proposed for precast component from multiple disciplines, production process requirements for factory components and construction \& lifting requirements ${ }^{[8]}$.

A detailed drawing of a precast component includes information such as outer contour of component, rebar, truss, embedded part, sleeve, door \& window, reserved hole, label, title bar, rebar list and embedded part list.

It is required to clear layer properties and their purposes (Table 1) based on the requirements for layer properties from MES, and strictly follow Table 1 when drawing Dxf drawings. According to comparative study, overlapped lines are not allowed. Otherwise, an error will be reported by the program in MES analysis, and the equipment cannot operate normally.

Table 1 Dxf Layer Properties and their Purposes

\begin{tabular}{|c|c|}
\hline $\begin{array}{c}\text { Layer } \\
\text { Properties }\end{array}$ & Purposes \\
\hline PC_Shape & $\begin{array}{c}\text { Outer contour of component after primary } \\
\text { spreading }\end{array}$ \\
\hline PC_Shape2 & $\begin{array}{c}\text { Outer contour of component after secondary } \\
\text { spreading }\end{array}$ \\
\hline Bar & Rebar arrangement \\
\hline Truss & Truss contour \\
\hline Door1 & Layer of 1\# door \\
\hline Door2 & Layer of 2\# door \\
\hline Window1 & Layer of 1\# window \\
\hline Window2 & Layer of 2\# window \\
\hline Defpoints & Labeling datum point \\
\hline DIM_LEAD & Callout line \\
\hline Bar_TAB & Rebar list \\
\hline PC_Part & Layer of embedded part \\
\hline Title bar & Title bar wireframe of drawing \\
\hline Embed_TAB & List of embedded part \\
\hline $\begin{array}{c}\text { Electric } \\
\text { appliance }\end{array}$ & Reservation and embedment of electrical \\
& appliance \\
\hline $\begin{array}{c}\text { Tapping and } \\
\text { sleeve }\end{array}$ & Reserved hole and reserved sleeve \\
\hline
\end{tabular}

\subsection{Text Message}

Prefabricated building drawing includes split \& detailed design specification of component, project split plan, detail of project assembling nodes, detail of project wall structure, project BOQ, structural detail of component, node detail of component, lifting detail of component and burying detail of embedded part of component ${ }^{[9]}$.

The split \& detailed drawing of a precast component includes information such as component name, component drawing No., drawing type, concrete grade, component type, concrete density, component weight, spreading amount and component thickness. Despite the title bar formats of all design organizations are extremely non-uniform, they can be standardized as the following format (Fig. 1) for standardization purpose, or special title bar can be customized by MES developer based on actual situation. Uniform text layer property is PUB PMSTEXT.

\begin{tabular}{|c|c|c|}
\hline $\begin{array}{c}\text { Component name } \\
\text { Plate }\end{array}$ & $\begin{array}{c}\text { Component drawing No. } \\
\text { JA-5-21 }\end{array}$ & $\begin{array}{c}\text { Drawing type } \\
1\end{array}$ \\
\hline $\begin{array}{c}\text { Concrete grade } \\
\text { C30 }\end{array}$ & DLB & Concrete density $\left(\mathrm{kg} / \mathrm{m}^{3}\right)$ \\
2385
\end{tabular}

Fig. 1 Format of Uniform Title Bar

Drawing type: " 1 " represents component drawing, and " 2 " represents rebar drawing. The filling rules of component type are as follows:

$\mathrm{B}=$ "B"; //1 floor slab

DLB = "DLB"; //1 floor slab (composite floor slab)

$\mathrm{WB}=$ "WB"; //2 roof slab

$\mathrm{KB}=$ "KB"; //3 hollow slab

$\mathrm{CB}=$ "CB"; //4 groove-shaped slab

$\mathrm{ZB}=$ "ZB"; //5 folded plate

$\mathrm{MB}=$ "MB"; //6 multi-ribbed plate

$\mathrm{TB}=$ "TB"; //7 stair tread

$\mathrm{GB}=$ "GB"; //8 (ditch) cover plate

$\mathrm{QB}=$ "QB"; //9 wallboard

TGB = "TGB"; //10 gutter board

$\mathrm{D}=$ "D"; //11 floor

$\mathrm{W}=$ "W"; //12 fence board

$\mathrm{L}=$ "L"; //13 beam

$\mathrm{WL}=$ "WL"; //14 roof beam

$\mathrm{DL}=$ "DL"; //15 crane beam

$\mathrm{QL}=$ "QL"; //16 ring beam

$\mathrm{GL}=$ "GL"; //17 lintel

$\mathrm{LL}=$ "LL"; //18 linking beam

$\mathrm{JL}=$ "JL"; //19 foundation beam

$\mathrm{TL}=$ "TL"; //20 stair beam

$\mathrm{LT}=$ "LT"; //21 purline

$\mathrm{Z}=$ "Z"; //22 column

$\mathrm{J}=$ "J"; //23 foundation

$\mathrm{ZH}=$ "ZH"; //24 pile

$\mathrm{T}=$ "T"; //25 stair

$\mathrm{YT}=$ "YT"; //26 balcony

$\mathrm{M}=$ "M"; //27 embedded part

\section{Preparing U File}

As an intermediate file developed by German Unitechnik Company for data exchange with automation equipment, $\mathrm{U}$ file provides production with various working files and information ${ }^{[10]}$.

According to research, $U$ file is composed of a fixed writing format and includes precast component type, boundary dimensions, rebar arrangement and sleeve information. The precast component information contained in $U$ file can be read through MES analysis. Since there are strict requirements for the writing format of $U$ file, it is inconvenient to be written manually, so it is commonly used for software output.

The writing format is as follows:

HEADER _ // Header record of the order

SLABDATE // Header record of the element part

CONTOUR // Header record of the contours

CUTOUT_ $/ /$ Header record for cutouts

geomotric date // Geomotric date 
MOUNPART // Header record for mounting parts geomotric date // Geomotric date

RODSTOCK // Header record for rod stock mounting date // Individual mounting parts BRGIRDER // Header record for braced girders rodstock date // Individual rodstock bars REFORCEM // Reinforcement braced girder date // Individual braced girders END // End

\section{Prefabricated Project - 7\# Building of Red Fort Lan Palace}

Taking Red Fort Lan Palace Project, Tangshan City, Hebei Province as an example (Fig. 2), 7\# building of this project has the gross aboveground floor area of 17,723.58 $\mathrm{m}^{2}$, and its precast components include 112 kinds of composite floor slabs and 4 kinds of prefabricated stairs. There is no vertical precast component. The assembly rate is $51 \%$. Precast component information was imported to MES by means of Dxf drawing and $U$ file.

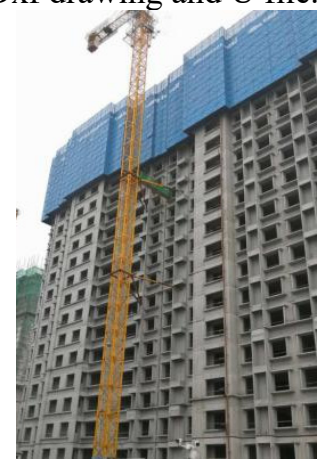

Fig. 2 Prefabricated Project - 7\# Building of Red Fort Lan Palace

\subsection{Drawing Dxf Drawing of 7\# Building of Red Fort Lan Palace}

For drawing of Dxf drawing, it is necessary to draw the contour of the precast component be referring to the structural drawing (Fig. 3) at first, and arrange rebar based on rebar drawing. Besides, overall consideration shall be made for reservation and embedment of disciplines such as building, structure, water, heating, electric, refined decoration and construction. Next, layer properties need to be matched based on Dxf requirements. Afterwards, factory production can be performed after successful MES analysis.

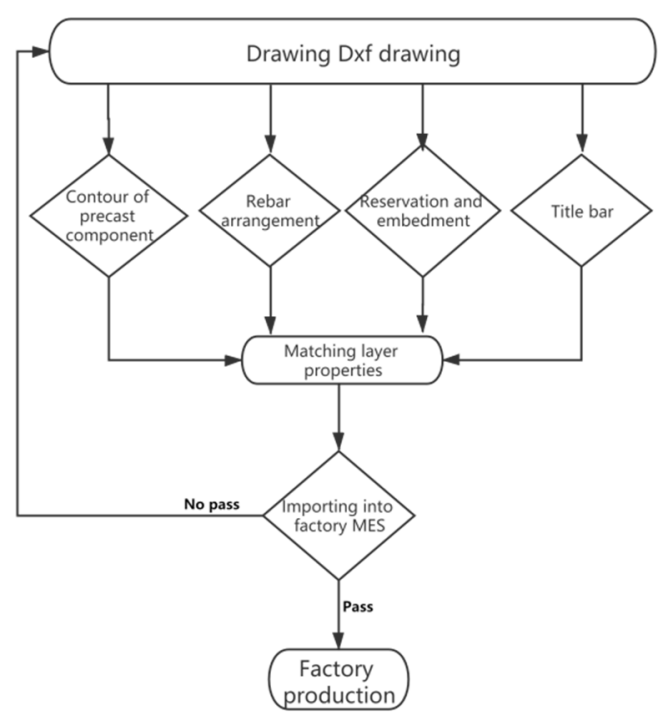

Fig. 3 Flow Chart for Drawing of Dxf Drawing

\subsection{Preparing U File of 7\# Building of Red Fort Lan Palace}

For preparing of a $\mathrm{U}$ file (Fig. 4), it is necessary to establish a PC model at first, and then, perform splitting, rebar arrangement, reservation and embedment based on design drawing, rebar drawing, M\&E drawing, refined decoration drawing and construction requirements. Finally, $U$ file shall be prepared directly with software (Fig. 5).

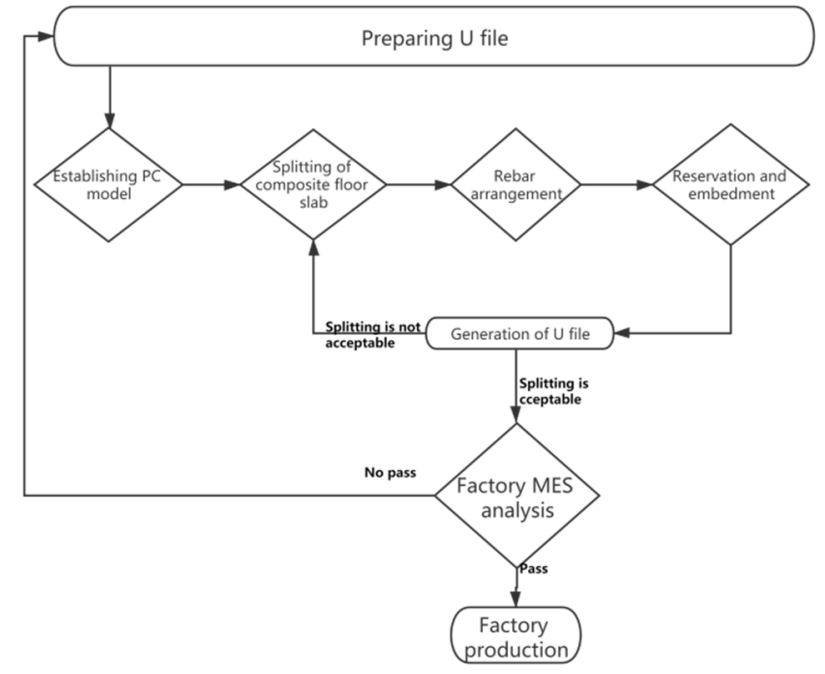

Fig. 4 Flow Chart for Preparing of U File
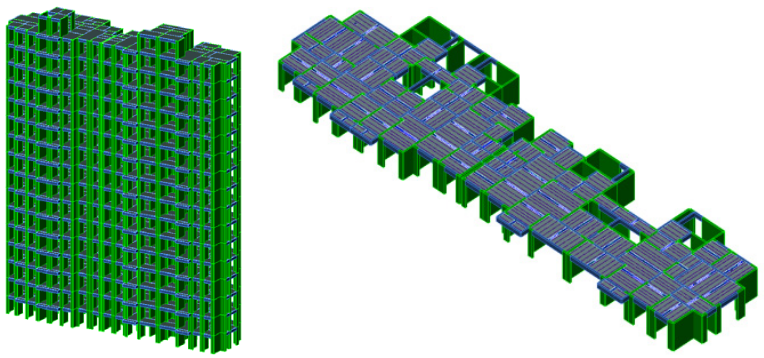

Fig. 5 PC Model, Detailed Design and Generation of U File 


\section{Comparison of Two Methods}

\subsection{Comparison of Components Covered}

Any kinds of precast components, including composite floor slab and prefabricated stair can be drawn with Dxf drawing. However, only composite floor slab is covered by $\mathrm{U}$ file, and no other precast components are supported.

Currently, prefabricated stair is manufactured by fixed die table with low informatization degree. For manufacturing of prefabricated wall, the types of precast components covered by $\mathrm{U}$ file are apparently inadequate.

\subsection{Comparison of Information Quality}

Repeated and redundant lines are easy to occur when Dxf drawing is applied. According to the statistics, there are 3 kinds of invalid floor slabs in 112 kinds of prefabricated floor slabs. If $\mathrm{U}$ file is used, the equipment needs to be commissioned at the first time, but there will be no quality problem during operation.

\subsection{Efficiency Comparison}

When Dxf drawing is applied, drawing of floor slab contour, rebar arrangement, truss position, opening rebar avoidance, reservation \& embedment and verification are necessary with the drawing efficiency of $7-10$ drawings/person/day and the total working hours of 20 persons-day. When $U$ file is applied, establishment of model, floor slab splitting, rebar arrangement rules, opening avoidance rules, reservation \& embedment and verification are necessary with the drawing efficiency of 20 - 40 drawings/person/day and the total working hours of 10 persons'day.

\subsection{Training Cost}

If Dxf drawing is applied, CAD training with the period $\leq 5$ days is necessary. If $\mathrm{U}$ file is applied, PC software training with the period $\geq 20$ days is needed.

\section{Conclusions}

This paper introduced two methods for PC factory to link with detailed design and production based on BIM technology: Dxf drawing and U file. They have obvious advantages and disadvantages: Dxf drawing is able to cover all kinds of precast components, easy for new comers to master, but the drawing efficiency is low. Currently, U file only supports composite floor slab, and it has a long training period, but it also has extremely low error rate and extremely high drawing efficiency.

Despite U file only supports composite floor slab at present, it will become an inevitable choice for realizing automation and informatization along with the development of the $U$ files of prefabricated inner/outer wall, prefabricated beam, prefabricated column and other components.
PC factory should continue to improve $u$ file, which can greatly improve work efficiency and reduce engineering errors.

\section{References}

1. XiaoKun Huang, ChunYu Tian, MoLin Wan. Researches and applicationgs of precast concrete strutres in China. J. Building Science, (2018)

2. General Office of the State Council.Guiding opinions of the general office of the State Council on vigorously developing prefabricated buildings. 000014349/2016-00194.EB. ISC〔2016〕71

3. CY331.Analysis on the development status and market prospect of China's PC component industry in 2020. www.chyxx.com

4. Da Jiang.Integrated applicationg of BIM technology in prefabricated building. J. Building Structiong ,24(2019).

5. Peng Gao, Jie Wang, JieYing Wu. BIM based design of a prefabricated concrete frame structure and analysis of key problems . J. Building structure,S2(2019)

6. Ministry of housing and urban rural development, national development and Reform Commission, Ministry of science and technology.Guiding opinions of the Ministry of housing and urban rural development and other departments on promoting the coordinated development of intelligent construction and building industrialization 000013338/2020-00264. EB. (2020)60

7. ShenHua Liu,WeiBing Xu.AutoCAD DXF file format and secondary development. J.Science \& Technology Information,(2017)

8. ShaoNan Sun, BingBing Sun, JiaWei Wu. BIM based collaborative evaluation of prefabricated building design stage. J. Yangtze River,04(2020)

9. YaJiang Huang, Ying Dong, ZiChen Zhang. Research on detailed design of prefabricated building structure based on BIM Technology. J.Construction Technology. S4(2018)

10. Unitechnik. Leitrechner Unicam 10.www.unitechnik-c 